\title{
ANÁLISE DA FORMALIDADE DOS SISTEMAS DE CONTROLE GERENCIAL EM EMPRESAS INCUBADAS
}

\section{ANALYSIS OF THE MANAGEMENT CONTROL SYSTEMS FORMALITY IN INCUBATED COMPANIES}

\begin{abstract}
RESUMO
Este estudo objetiva analisar a formalidade dos Sistemas de Controle Gerencial (SCG) em empresas incubadas. Uma pesquisa de levantamento foi realizada nas incubadoras de empresas associadas à Associação Nacional de Entidades Promotoras de Empreendimentos Inovadores (Anprotec). Um questionário formatado no Google Docs foi enviado às incubadoras de empresas para que fosse enviado aos gestores das empresas incubadas, obtendo-se respostas de 15 gestores de empresas incubadas. O questionário compõe-se de três blocos: perfil do respondente, características da empresa incubada participante da pesquisa e questões sobre a formalização de elementos dos SCG propostos por Malmi e Brown (2008). Aplicaram-se estatísticas descritivas, medidas centrais como média, mediana, moda e desvio padrão. Os resultados da pesquisa denotam maior formalização no controle de planejamento e controle cultural em detrimento do controle administrativo e controle cibernético. As evidências indicam que as empresas pesquisadas priorizam o planejamento de metas e ações de curto prazo, com foco tático, e controles informais, enraizados em crenças e valores, em detrimento dos controles formais, exercidos a partir do estabelecimento de medidas explícitas e verificáveis. No entanto, vale ressaltar que a adoção de controles gerenciais formais na fase inicial é importante para o crescimento de jovens empresas, no caso de empresas incubadas.
\end{abstract}

Palavras-chave: formalidade; sistemas de controle gerencial; empresas incubadas.

\begin{abstract}
The objective of this study is to analyze the formality of the Management Control Systems (MCS) in incubated companies. A survey was conducted in the incubators of companies associated with the National Association of Entities Promoting Innovative Enterprises (ANPROTEC). A Google Docs-formatted questionnaire was sent to the incubators of companies; it was intended for managers and 15 of them responded. The questionnaire consists of three blocks: respondent profile, characteristics of the incubated company participating in the research, questions about the formalization of MCS elements proposed by Malmi and Brown (2008). Descriptive statistics, mean, median, mode and standard deviation were applied. Research results denote greater formalization in planning and cultural controls in detriment of administrative and cybernetic controls. Evidence indicates that the companies surveyed prioritize the planning of short-term goals and actions, with tactical focus and informal controls rooted in beliefs and values in detriment of formal controls, exercised through the establishment of explicit and verifiable measures. However, it is worth mentioning that in the case of young incubated companies, the adoption of formal management controls in the initial phase is important for growth.
\end{abstract}

Keywords: formality; management control systems; incubated companies.

\section{Ilse Maria Beuren}

Doutora em Controladoria e Contabilidade pela FEA/USP. Professora do Programa de Pós-Graduação em Contabilidade da Universidade Federal de Santa Catarina (UFSC). Contato: Universidade Federal de Santa Catarina, Campus Reitor João David Ferreira Lima, s/n, Bairro Trindade, Florianópolis, SC, Brasil, CEP: 88040-970. E-mail: ilse.beuren@gmail.com

\section{Vanderlei dos Santos}

Doutorando do Programa de Pós-Graduação em Contabilidade da Universidade Federal de Santa Catarina (UFSC). Professor da Universidade do Estado de Santa Catarina (Udesc). Contato: Universidade Federal de Santa Catarina, Campus Reitor João David Ferreira Lima, s/n, Bairro Trindade, Florianópolis, SC, Brasil, CEP 88040-900.

E-mail: vanderleidossantos09@gmail.com

\section{Viviane Theiss}

Doutoranda do Programa de Pós-Graduação em Contabilidade da Universidade Federal de Santa Catarina (UFSC). Contato: Universidade Federal de Santa Catarina, Campus Reitor João David Ferreira Lima, s/n, Bairro Trindade, Florianópolis, SC, Brasil, CEP 88040-900. E-mail: theissviviane@gmail.com 


\section{INTRODUÇÃO}

Um sistema de controle gerencial compõe-se de sistemas de controle formais e informais de uma empresa, que trabalham em conjunto (OTLEY, 1980). Os controles formais, como orçamentos, são úteis para auxiliar o planejamento e restringir inovações, enquanto os controles informais fornecem informações amplas, de maneira flexível (CHENHALL, 2003). Portanto, os SCG, se desenhados de forma adequada, podem ser usados para implementar estratégias de criação de valor para a empresa (HENRI, 2006).

Nessa perspectiva, Henri (2006) investigou a influência do uso de SCG na obtenção de inovação, aprendizagem organizacional, orientação para o mercado e empreendedorismo. Oyadomari (2008), respaldado no modelo de Henri (2006), averiguou a existência e qualificou as relações entre o uso de SCG e as competências organizacionais (aprendizagem organizacional, orientação para o mercado, inovação e empreendedorismo), além de verificar como essas relações impactam no desempenho econômico de empresas brasileiras de grande porte. Alves (2010) realizou um estudo de caso para identificar a contribuição dos SCG para a formação e implementação da estratégia organizacional, considerando as dimensões de desenho, com a aplicação do modelo de Malmi e Brown (2008), e de uso dos SCG, com a aplicação do modelo de Simons (1995).

Diferentes modelos teóricos de SCG são abordados na literatura. Simons (1995) propõe quatro alavancas de controle - crenças, limites, diagnóstico e interativo: sistema de crença, no qual são estabelecidos os valores centrais da organização; sistema de limites, para o estabelecimento de restrições comportamentais; sistema diagnóstico, para a realização de monitoramento e análise de variações; e sistema interativo, para o envolvimento da gerência, flexibilidade para com as atividades realizadas e um olhar para o futuro. Para Widener (2007), a capacidade de essas alavancas alcançarem as estratégias da empresa não reside em analisá-las de forma isolada, mas no fato de serem forças que criam uma tensão dinâmica.

O framework de Ferreira e Otley (2009) compreende um conjunto de indicadores, com destaque para: papel da visão e missão, fatores-chave de sucesso, influência da estrutura dos SCG na organização, técnicas de avaliação de desempenho, medidas-chave de desempenho da organização, extensão da mudança dos SCG e extensão das técnicas de quadro de coerência. Já Malmi e Brown (2008) desenvolveram um quadro teórico denominado Pacote de SCG, que adota cinco formas de abordagens de controle: planejamento; cibernético; recompensa e compensação; administrativo e cultural. Um pacote de SCG é uma coleção ou um conjunto de controles e sistemas de controles (MALMI; BROWN, 2008).

Grabner e Moers (2013) explicam que o pacote de controle gerencial decorre das múltiplas práticas de controle existentes ao mesmo tempo nas organizações. A tipologia de Malmi e Brown (2008) fornece uma lista (não exaustiva) de práticas de controle gerencial que podem ser incluídas em um pacote, cada uma delas agrupadas em uma categoria específica, para orientar a pesquisa futura. Esta perspectiva sobre o controle de gestão não depende de uma teoria particular que explique possíveis interdependências entre escolhas de controle porque o objetivo é fornecer uma visão mais holística das práticas de controle gerencial, e não a interdependência entre elas (GRABNER; MOERS, 2013).

Contudo, o uso da tipologia proposta por Malmi e Brown (2008) ainda é embrionário nas pesquisas, voltado, principalmente, para grandes empresas. Bedford, Malmi e Sandelin (2016), por exemplo, pesquisaram empresas australianas com, no mínimo, 100 funcionários e receitas de pelo menos 20 milhões de dólares, no intuito de examinar os pacotes de controle gerencial que são eficazes nos contextos estratégicos defensor e prospector. Roetzel, Stehle e Pedell (2014) investigaram, em grandes empresas alemãs, o reflexo das estratégias ambientais nos sistemas de controle e no desempenho gerencial ambiental. Beuren e Vaz (2016) investigaram uma amostra de 73 empresas listadas entre as 150 melhores para se trabalhar no Brasil no ano de 2014, conforme o ranking da revista Exame de 2015.

Assim, percebe-se uma lacuna de pesquisas relacionadas a novos formatos organizacionais, como é o caso das incubadoras e as empresas incubadas. Para Bergek e Norrman (2008), as incubadoras de empresas possuem os seguintes propósitos: a) fornecer espaço compartilhado e estrutura para as incubadas; b) desenvolver um conjunto de atividades de apoio comum para reduzir custos das incubadas; c) conceder apoio empresarial às incubadas; e d) formar redes para o desenvolvimento e crescimento no mercado de atuação das incubadas. Esse apoio gerencial das incubadoras para as empresas incubadas perpassa o planejamento e controle das partes envolvidas. Nesse sentido, identificaram-se alguns estudos com o intuito de compreender as particularidades das incubadoras e empresas incubadas no que concerne ao processo de gestão, inovação e controle.

Costa, França e Teixeira (2010) pesquisaram o apoio gerencial oferecido pela Incubadora Cise aos empreendimentos de base tecnológica em fase de incubação. Os resultados indicaram que: (i) a incubadora vem atendendo parcialmente às suas necessidades, especialmente com relação à falta de consultoria/assessoria; (ii) o apoio na gestão de seus negócios permitiria que o projeto inicial de ingresso fosse desenvolvido e aprimorado e, assim, seria possível enfocar o aspecto estratégico do negócio, e não o operacional. Raupp e Beuren (2011) investigaram o suporte oferecido pelas incubadoras brasileiras às empresas incubadas e destacaram-se: apoio jurídico, orientação empresarial e mercadológica, apoio na captação de recursos e custos compartilhados durante o processo de incubação.

Sobre as vantagens das startups abrigarem-se em incubadoras de empresas, Machado et al. (2016) identificaram em sua pesquisa que o capital estrutural tem influência no sucesso das startups incubadas, principalmente no que se refere ao apoio físico e tecnológico recebido das incubadoras. Cassol et al. (2016) analisaram se a capacidade absortiva influencia na inovação de empresas incubadas e graduadas do estado de Santa Catarina. Cassol, Zapalai e Cintra (2017) examinaram o efeito moderador da capacidade absortiva na relação entre o capital intelectual e a inovação em empresas incubadas. 
No que diz respeito ao controle gerencial, Amorim et al. (2016) analisaram a relação entre o sistema de controle orçamentário, sob a lente do modelo das alavancas de Simons (1995), e a inovação, em empresas de base tecnológica incubadas. Lopes, Beuren e Martins (2018) verificaram o alinhamento da intensidade de uso de instrumentos do sistema de controle gerencial com o nível da inovação de produtos e processos. Por sua vez, Davila, Foster e Jia (2015) analisaram em que medida empresas startups que possuem SCG alinhados conseguem mais facilmente obter investimentos de capital.

Com base no exposto, neste estudo, busca-se responder à seguinte questão de pesquisa: qual é o grau de formalidade dos controles de planejamento, cibernético, recompensa e compensação, administrativo e cultural em empresas incubadas? Assim, este estudo objetiva analisar a formalidade dos Sistemas de Controle Gerencial em empresas incubadas, pautado no Pacote de SCG proposto por Malmi e Brown (2008).

Na perspectiva teórica, busca-se contribuir para estudos que analisam o grau de formalidade dos SCG em empresas incubadas, ou seja, à medida que os propósitos das incubadoras de empresas se manifestam na rotina organizacional das empresas incubadas, há oportunidades para o desenvolvimento de pesquisas que se propõem a analisar esse fenômeno. A formalidade dos SCG nesse contexto abre novas lacunas de pesquisa, incluindo seu efeito nos propósitos do formato organizacional no qual as incubadas estão inseridas.

A importância prática deste estudo está em oferecer reflexões para melhorar o projeto do desenho e uso dos SCG, voltados ao desenvolvimento das atividades realizadas pelas empresas incubadas. Geralmente, trata-se de empresas startups, sobre as quais acredita-se que a presença formal de SCG melhora as decisões, assim como o seu potencial de qualidade e crescimento futuro. Nessa perspectiva, as dimensões dos SCG exploradas na pesquisa estão amparadas pelas categorias presentes no estudo de Malmi e Brown (2008).

\section{REVISÃO BIBLIOGRÁFICA}

\subsection{Sistemas de Controle Gerencial}

O controle gerencial é definido por Anthony (1965) como um processo que guia um conjunto de variáveis para atingir a meta preconcebida ou o objetivo. Já os SCG, para esse autor, compreendem três elementos principais: planejamento estratégico, controle de gestão e controle de tarefas. O planejamento estratégico é a função para a definição de objetivos, estratégias e políticas de uma organização, enquanto o controle de tarefas é usado para garantir que as tarefas especificadas sejam realizadas como planejado (ANTHONY, 1965).

De acordo com Chenhall (2003), a definição de SCG tem evoluído ao longo dos anos a partir de uma visão centrada na prestação de informações formais por parte das organizações, mas considerada, por uma vertente sociológica, como ativa, ao proporcionar aos indivíduos poder para alcançar seus próprios fins. Informações formais, conforme Chenhall (2003, p. 129), incluem "informações externas relacionadas ao mercado, como clientes e concorrentes; informações não-financeiras, relacionadas a processos de produção; informações preditivas; e uma ampla gama de mecanismos de apoio à decisão e controles informais pessoais e sociais”.

Todos esses controles podem fazer parte dos SCG da empresa, mas, para tal, devem estar desenhados conforme os parâmetros desejados. Malmi e Brown (2008) advertem sobre a necessidade de esclarecer quais são as definições de parâmetros de SCG desejados pela empresa, o que implica definir o que será incluído, deixado de fora e as razões das escolhas, além de como o pacote de controle irá operar e será usado pela empresa.

Simons (1995) propôs uma tipologia de SCG que incorpora aspectos sociais e organizacionais para suas abordagens econômicas, considerando os controles de crenças e limites e os controles diagnóstico e interativo. Ferreira e Otley (2009) estabeleceram indicadores-chave: o papel da visão e missão, fatores-chave de sucesso, influência da estrutura das organizações de SCG, técnicas de avaliação de desempenho, medidas-chave de desempenho da organização, extensão da mudança dos SCG e extensão das técnicas de quadro de coerência. Malmi e Brown (2008) desenvolveram um quadro teórico denominado de SCG como um pacote, com cinco formas de controle: planejamento; cibernético; recompensa e compensação; administrativo e cultural.

\subsection{Modelo Teórico de Malmi e Brown (2008)}

O desenho dos SCG refere-se à dimensão que caracteriza os seus aspectos teóricos (MALMI; BROWN, 2008). Os SCG não operam isoladamente, o que implica considerar o fenômeno como um todo. Fisher (1998) argumenta que, se as ligações entre os SCG não são reconhecidas, a maneira como os componentes dos SCG são operacionalizados levará a conclusões erradas. Malmi e Brown (2008) aduzem que essa visão contribui para explicar o seu desenvolvimento, adoção e uso, uma vez que podem influenciar quaisquer conclusões extraídas do funcionamento do pacote dos SCG.

Compreender os SCG como um pacote pode contribuir para projetar controles para apoiar os objetivos da organização, as atividades de controle, e impulsionar o desempenho organizacional (MALMI; BROWN, 2008). A força da tipologia situa-se no âmbito dos controles dos SCG como um pacote, em vez da profundidade da sua discussão dos sistemas individuais, conforme demonstrado na Figura 1. 
Figura 1 - Pacote de Sistemas de Controle Gerencial

\begin{tabular}{|c|c|c|c|c|c|c|}
\hline \multicolumn{7}{|c|}{ Cultural } \\
\hline \multicolumn{2}{|c|}{ Grupo } & \multicolumn{3}{|c|}{ Valores } & \multicolumn{2}{|c|}{ Símbolos } \\
\hline \multicolumn{2}{|c|}{ Planejamento } & \multicolumn{4}{|c|}{ Cibernético } & \multirow{2}{*}{$\begin{array}{r}\text { Recompensa e } \\
\text { compensação }\end{array}$} \\
\hline $\begin{array}{c}\text { Planejamento } \\
\text { estratégico }\end{array}$ & $\begin{array}{c}\text { Planejamento } \\
\text { operacional }\end{array}$ & Orçamentos & $\begin{array}{l}\text { Controles } \\
\text { financeiros }\end{array}$ & $\begin{array}{l}\text { Controles não } \\
\text { financeiros }\end{array}$ & $\begin{array}{l}\text { Controles } \\
\text { híbridos }\end{array}$ & \\
\hline \multicolumn{7}{|c|}{ Administrativo } \\
\hline \multicolumn{2}{|c|}{ Estrutura de Governança } & \multicolumn{3}{|c|}{ Estrutura organizacional } & \multicolumn{2}{|c|}{ Políticas e procedimentos } \\
\hline
\end{tabular}

Fonte: Malmi e Brown (2008, p. 291).

Observa-se, na Figura 1, a concepção dos SCG como um pacote que compreende cinco tipos de controles: planejamento, cibernético, recompensa e compensação, administrativo e cultural. Considerando esse conjunto de elementos holísticos, tem-se a oportunidade de congregar todos os elementos presentes nos SCG a partir do inter-relacionamento entre os cinco elementos da tipologia. Malmi e Brown (2008) apontam os elementos, a conceituação e os componentes desse pacote, conforme exposto no Quadro 1.

Quadro 1 - Conceituação dos elementos do Pacote dos SCG

\begin{tabular}{|c|c|c|}
\hline Elementos & Conceituação & Componentes \\
\hline Planejamento & $\begin{array}{l}\text { - Objetivos das áreas funcionais da organização, ori- } \\
\text { entando esforço e comportamento; } \\
\text { - Padrões a serem alcançados em relação às metas; } \\
\text { - Objetivos alinhados em todas as áreas funcionais } \\
\text { da organização. }\end{array}$ & $\begin{array}{c}\text { Planejamento de metas e ações para o curto } \\
\text { prazo, com foco tático. Planejamento de alcance } \\
\text { de metas e ações de médio e longo prazo, com } \\
\text { foco estratégico. }\end{array}$ \\
\hline Cibernético & $\begin{array}{l}\text { - Medidas que permitem a quantificação de um fenôme- } \\
\text { no subjacente, atividade ou sistema; } \\
\text { - Padrões de desempenho ou metas a serem cumpridas; } \\
\text { - Processo de feedback que permite a comparação dos } \\
\text { resultados das atividades com o padrão estabelecido. }\end{array}$ & $\begin{array}{l}\text { Orçamentos, Medidas financeiras, Medidas não } \\
\text { financeiras, Medidas híbridas (contêm tanto } \\
\text { medidas financeiras como não financeiras). }\end{array}$ \\
\hline $\begin{array}{l}\text { Recompensa e } \\
\text { compensação }\end{array}$ & $\begin{array}{l}\text { - Motivar e aumentar o desempenho dos indivíduos e } \\
\text { grupos com recompensas, controlando a direção, du- } \\
\text { ração e intensidade do esforço. }\end{array}$ & $\begin{array}{c}\text { Estipular recompensas e/ou compensações para } \\
\text { a realização de metas. }\end{array}$ \\
\hline Administrativo & $\begin{array}{l}\text { - Organização de indivíduos (projeto de organização } \\
\text { e estrutura); } \\
\text { - Monitoramento do comportamento e dos responsáveis } \\
\text { pelo monitoramento (governança); } \\
\text { - Especificação dos comportamentos/tarefas que devem ser } \\
\text { executadas ou não realizadas (políticas e procedimentos). }\end{array}$ & $\begin{array}{l}\text { Desenho da estrutura organizacional, estrutura de } \\
\text { governança da empresa, políticas e procedimentos. }\end{array}$ \\
\hline Cultural & $\begin{array}{l}\text { - Valores, crenças e normas sociais que influenciam o } \\
\text { comportamento dos funcionários. }\end{array}$ & $\begin{array}{l}\text { Controles baseados em valor, controles dos } \\
\text { grupos e símbolos. }\end{array}$ \\
\hline
\end{tabular}

Fonte: Adaptado de Malmi e Brown (2008).

Observa-se, no Quadro 1, os elementos propostos no Pacote de SCG. O controle de planejamento tem importância na definição de metas, fornecimento de padrões e alinhamento dos objetivos. Para Malmi e Brown (2008), o planejamento ajuda as empresas em relação ao controle para a sua continuidade e crescimento. Dentre as finalidades, destaca-se a definição de metas nas áreas funcionais, fornecimento de padrões a serem alcançados em relação aos objetivos, níveis de esforços e alinhamento de comportamentos dos membros da organização (MALMI; BROWN, 2008).

O controle cibernético compreende processos de ciclos de feedback, representados por padrões de desempenho, para a medição, comparação, realimentação de informações, correção e modificação nos sistemas (MALMI; BROWN, 2008). Para esses autores, trata-se desde um sistema de informação de apoio à decisão até SCG, representados, por exemplo, por medidas financeiras, medidas não financeiras, medidas híbridas. 
As recompensas e compensações são consideradas pelas empresas para motivar e melhorar o desempenho de indivíduos e grupos, conforme os objetivos e atividades da organização. Para os autores, mesmo que as recompensas e compensações estejam ligadas ao controle cibernético, elas são elementos distintos (MALMI; BROWN, 2008).

O controle administrativo caracteriza-se por sistemas de controle atrelados ao comportamento das responsabilidades dos funcionários, por meio da organização de indivíduos e grupos, do mesmo modo que estabelecem os processos de especificação das tarefas que devem ou não ser realizadas (MALMI; BROWN, 2008).

O controle administrativo, segundo Malmi e Brown (2008), compreende três grupos: (i) concepção e estrutura da organização, ou seja, uma estrutura particular para a organização, que pode encorajar certos tipos de contatos e relacionamentos; (ii) estrutura de governança, que inclui as linhas formais das autoridades e responsabilidades da empresa (estrutura de topo da empresa, composição dos conselhos, equipes de gestão e de projetos, sistemas), para garantir que os representantes das várias funções e unidades organizacionais reúnam-se e coordenem as suas atividades; e (iii) procedimentos e políticas adotados pela empresa, que especificam os processos e comportamentos dentro da organização, como práticas, procedimentos operacionais padrões, regras e restrições comportamentais.

Por fim, o controle cultural é usado para regular o comportamento. Para Malmi e Brown (2008), o controle cultural pode ser considerado sob três aspectos: controles baseados em valor, símbolos e do clã. Os controles baseados em valor, conforme Simons (1995, p. 34), são considerados um "conjunto explícito de definições organizacionais que os gerentes seniores comunicam e reforçam sistematicamente para fornecer valores básicos, propósito e direção para a organização". São exemplos de crenças que transmitem valores: as declarações de missão, visão, credos e declarações de propósitos (SIMONS, 1995). Os símbolos são expressões visíveis da organização, por exemplo, uso de uniformes e concepção do espaço de trabalho, com o intuito de demonstrar o profissionalismo da empresa (SCHEIN, 1997). Os controles de clã decorrem de subculturas ou grupos distintos dentro da organização, com habilidades e valores que são expostos a um processo de socialização, por exemplo, uma unidade organizacional ou uma profissão (OUCHI, 1979).

Desse modo, este estudo apresentou os elementos do Pacote de SCG, conforme proposto por Malmi e Brown (2008), composto de controles de planejamento, cibernético, recompensa e compensação, administrativo e cultural. O arcabouço teórico deste estudo foi elaborado em consonância com os fundamentos necessários para aferir a formalidade dos SCG em empresas incubadas.

\section{PROCEDIMENTOS METODOLÓGICOS}

Esta pesquisa descritiva com abordagem quantitativa foi realizada a partir de um levantamento das incubadoras de empresas associadas à Associação Nacional de Entidades Promotoras de Empreendimentos Inovadores (Anprotec). Um questionário formatado no Google Docs foi enviado às incubadoras de empresas, no período de dezembro de 2016 a março de 2017, para que fosse enviado aos gestores das empresas incubadas. Nesse período, obteve-se resposta ao questionário por parte de 15 gestores de empresas incubadas.

O questionário enviado às incubadoras para aplicação nas empresas incubadas compõe-se de três blocos. O primeiro refere-se a dados sobre o perfil do respondente, com indagações sobre o gênero, idade, formação, função que exercem nas empresas incubadas e o tempo em que estão nessa função. O segundo diz respeito às características das empresas incubadas respondentes da pesquisa, buscando conhecer o setor de atuação, o número de funcionários e o valor de aporte realizado pelo fundo de investimento nessas empresas. O terceiro bloco do questionário consistiu de questões sobre a formalização de elementos dos SCG, fundamentado em Malmi e Brown (2008) e Theiss e Beuren (2017).

As assertivas deste último bloco foram mensuradas por meio de itens múltiplos, com escala Likert de sete pontos, variando de "discordo totalmente" a "concordo totalmente" para as variáveis de controle de planejamento, controle cibernético, controle administrativo e controle cultural (Quadro 2). No presente estudo, as recompensas e compensações foram desconsideradas, por se tratar de empresas geralmente administradas pelos fundadores.

\section{Quadro 2 - Construto da pesquisa}

\begin{tabular}{|c|c|}
\hline Variáveis & Assertivas \\
\hline $\begin{array}{l}\text { Controle de } \\
\text { Planejamento }\end{array}$ & $\begin{array}{l}\text { Definição das metas das áreas funcionais da organização para orientar os esforços e comportamentos. } \\
\text { Fornecimento dos padrões a serem alcançados em relação à meta, deixando claro o nível de esforço e } \\
\text { comportamento esperado. } \\
\text { Alinhamento dos objetivos, por meio das áreas funcionais da organização, com vistas a controlar as } \\
\text { atividades de grupos e indivíduos. }\end{array}$ \\
\hline Controle Cibernético & $\begin{array}{l}\text { Medidas que permitam a quantificação de um fenômeno subjacente ou das atividades do sistema. } \\
\text { Padrões de desempenho ou metas a serem cumpridos. } \\
\text { Processo de feedback que permite a comparação do resultado das atividades com o padrão. } \\
\text { Realimentação do sistema a partir de informações de feedback quantitativas e qualitativas. } \\
\text { Capacidade de modificar o comportamento do sistema ou de atividades subjacentes. }\end{array}$ \\
\hline
\end{tabular}




\begin{tabular}{|c|c|}
\hline Variáveis & Assertivas \\
\hline \multirow{4}{*}{$\begin{array}{c}\text { Controle } \\
\text { Administrativo }\end{array}$} & $\begin{array}{l}\text { Direção para o comportamento da força de trabalho por meio da organização dos indivíduos } \\
\text { (desenho organizacional e estrutura). }\end{array}$ \\
\hline & $\begin{array}{l}\text { Monitoramento do comportamento dos empregados e dos responsáveis pelo seu monitoramento } \\
\text { (governança). }\end{array}$ \\
\hline & $\begin{array}{c}\text { Especificação de como as tarefas ou comportamentos devem ser realizados ou não realizados } \\
\text { (políticas e procedimentos). }\end{array}$ \\
\hline & $\begin{array}{l}\text { Agenda de reuniões executivas que estabelecem prazos e direcionam o comportamento dos membros } \\
\text { da organização. }\end{array}$ \\
\hline \multirow{4}{*}{ Controle Cultural } & Valores, crenças e normas sociais que são estabelecidos e influenciam o comportamento da força de trabalho. \\
\hline & Procedimentos para recrutar e selecionar pessoas seguem os valores da organização. \\
\hline & Explicação do comportamento e dos valores organizacionais desejados se refletem na força de trabalho. \\
\hline & Hábitos de comunicação e de colaboração são meios de controlar o comportamento da força de trabalho. \\
\hline
\end{tabular}

Fonte: Elaborado com base em Malmi e Brown (2008) e Theiss e Beuren (2017).

Para o envio do instrumento de pesquisa, fez-se um levantamento no site da Anprotec das incubadoras de empresas associadas, endereços físicos e contatos telefônicos e eletrônicos. O questionário foi encaminhado para o endereço eletrônico das instituições listadas. Em vista da dificuldade de obter respostas, realizou-se uma força-tarefa para contatar por telefone os gestores das incubadoras, explicar o objetivo da pesquisa e solicitar a sua colaboração para que as empresas incubadas respondessem ao questionário.

Os dados coletados nas empresas incubadas via questionário, por intermédio das incubadoras de empresas, foram tabulados e analisados no Software Microsoft Excel ${ }^{\circledR}$. Aplicaram-se estatísticas descritivas, basicamente medidas centrais, como média, mediana, moda e desvio padrão.

\section{RESULTADOS E DISCUSSÃO}

\subsection{Perfil dos gestores respondentes da pesquisa}

Na Tabela 1, evidencia-se o perfil dos respondentes da pesquisa, destacando a faixa etária, formação, função que exercem nas empresas incubadas, tempo na função e gênero.

Tabela 1 - Perfil dos respondentes

\begin{tabular}{cccc}
\hline Faixa Etária & Qtde & Formação & Qtde \\
\hline 31 a 40 anos & 6 & Graduação & 2 \\
41 a 50 anos & 5 & Especialização/MBA & 5 \\
Acima de 50 anos & 4 & Mestrado/Doutorado & Qtde \\
\hline Função & Qtde & Tempo na função & 3 \\
\hline CEO/CFO & 7 & Até 1 ano & 1 \\
Diretor & 6 & 1 a 5 anos & 5 \\
\hline Gerente/Administrador & 2 & 6 a 10 anos & 1 \\
\hline Gênero & Qtde & 10 a 15 anos & 3 \\
\hline Fasculino & 14 & 16 a 20 anos & 21 a 25 anos \\
\hline
\end{tabular}

Fonte: Dados da pesquisa.

Observa-se, na Tabela 1, que os gestores/responsáveis pelas empresas incubadas são, em quase sua totalidade, do gênero masculino. Há uma distribuição homogênea nas faixas etárias, sendo que o gestor mais jovem tem 31 anos 
e o que apresenta maior idade está com 67 anos. Todos esses gestores possuem nível superior, sendo que a maioria (8) já realizou algum curso de pós-graduação em nível de especialização ou MBA. Cinco respondentes possuem curso de pós-graduação stricto sensu, sendo três com mestrado e dois com doutorado. De acordo com o entendimento de Cassol et al. (2016), esses dados podem sinalizar que, entre as empresas, há um potencial de conhecimento prévio sobre a área de atuação e a condição de competividade de cada uma dessas empresas, dada a alta escolaridade dos respondentes.

Em relação às funções exercidas, seis deles são Chief Executive Officer (CEO) e um deles é Chief Financial Officer (CFO). Há, também, seis diretores, sendo dois do setor financeiro, outro industrial, e outros três não especificaram a área organizacional. Além disso, há um respondente que exerce a função de gerente financeiro e outro que exerce a função de administrador financeiro. Observa-se, ainda, que o tempo em que os respondentes exercem a função é variado, sendo que o menor tempo apontado é de seis meses e o maior é de 23 anos. Esse perfil sugere que os respondentes reúnem as condições necessárias para aferir a formalidade dos SCG como um pacote, conforme preconizado por Malmi e Brown (2008).

\subsection{Características das empresas pesquisadas}

No bloco do questionário relativo às características das empresas, indagou-se sobre o setor de atuação, o número de funcionários e o valor de aporte realizado pelo fundo de investimento nessas empresas. Os resultados estão sintetizados na Tabela 2.

Tabela 2 - Características das empresas

\begin{tabular}{|c|c|c|c|}
\hline Setor de Atuação & Qtde & Valor de aporte do fundo de investimento & Qtde \\
\hline Tecnologias da informação e da comunicação & 7 & Até $\mathrm{R} \$ 1$ milhão & 2 \\
\hline Biotecnologia & 2 & De $\mathrm{R} \$ 1$ a $\mathrm{R} \$ 2$ milhões & 5 \\
\hline Outros & 6 & De $R \$ 2$ a $R \$ 3$ milhões & 5 \\
\hline N. ${ }^{\circ}$ de funcionários & Qtde & Acima de $\mathrm{R} \$ 3$ milhões & 1 \\
\hline 1 a 9 funcionários & 4 & Não divulgado & 2 \\
\hline 10 a 20 funcionários & 5 & & \\
\hline 21 a 50 funcionários & 2 & & \\
\hline Acima de 50 funcionários & 4 & & \\
\hline
\end{tabular}

Fonte: Dados da pesquisa.

Constata-se, na Tabela 2, que sete empresas atuam no setor de tecnologias da informação e comunicação e duas atuam no setor de biotecnologia. Tal constatação é condizente com as características das empresas incubadas, que, geralmente, possuem caráter inovador e são oriundas de pesquisas científicas e/ou tecnológicas, conforme apontado por Iacono, Almeida e Nagano (2011). Outras seis empresas atuam em setor específico: na área da saúde; óleo e gás; novos materiais; desenvolvimento, fabricação, instalação de sistemas de equipamentos; educação; e saúde, tecnologia, indústria e gestão de saúde ambiental.

Observa-se, ainda, que o número de funcionários é distinto nessas empresas, sendo que há uma organização com um funcionário e outra com 100 funcionários. As empresas de tecnologias da informação e comunicação também apresentam números variados de funcionários: algumas delas com nove (duas empresas) e outras indicaram ter 30, 50, 89 funcionários. Contudo, a maioria delas são empresas pequenas e possuem até 20 funcionários. Essa distinção no número de funcionários pode estar atrelada ao estágio de incubação. Na pesquisa realizada por Conte, Beuren e Santos (2016), foi constatado que as empresas em estágio inicial praticamente não possuem funcionários nem apresentam faturamento. Geralmente, nesse estágio, a concentração está no desenvolvimento do projeto, no processo de criação e desenvolvimento de produtos.

Denota-se, também, que o valor do aporte do fundo de investimento foi distinto entre as organizações, variando de R\$ 1 milhão até R\$ 3,5 milhões. Tal fato pode estar relacionado com os interesses dos fundos de investimentos, com a magnitude e a amplitude dos projetos das incubadas, área de atuação, público-alvo e benefícios para a sociedade como um todo.

\subsection{Formalidade do Sistema de Controle Gerencial em empresas incubadas}

Na Tabela 3, apresenta-se a estatística descritiva (média, mediana, moda e desvio padrão) referente à formalidade dos SCG das empresas incubadas, analisados a partir da abordagem de pacote preconizado por Malmi e Brown (2008). 
Tabela 3 - Formalidade dos SCG como um Pacote nas empresas incubadas

\begin{tabular}{|c|c|c|c|c|c|}
\hline Controles & Descrição & Média & Mediana & Moda & D. padrão \\
\hline \multirow{3}{*}{ Planejamento } & $\begin{array}{l}\text { Definição das metas das áreas funcionais da organi- } \\
\text { zação para orientar os esforços e comportamentos. }\end{array}$ & 5,07 & 5,00 & 5,00 & 1,49 \\
\hline & $\begin{array}{l}\text { Fornecimento dos padrões a serem alcançados em } \\
\text { relação à meta, deixando claro o nível de esforço e } \\
\text { comportamento esperado. }\end{array}$ & 4,20 & 5,00 & 5,00 & 1,61 \\
\hline & $\begin{array}{l}\text { Alinhamento dos objetivos, por meio das áreas } \\
\text { funcionais da organização, com vistas a controlar as } \\
\text { atividades de grupos e indivíduos. }\end{array}$ & 4,80 & 5,00 & 5,00 & 1,42 \\
\hline \multirow{5}{*}{ Cibernético } & $\begin{array}{l}\text { Medidas que permitam a quantificação de um } \\
\text { fenômeno subjacente ou das atividades do sistema. }\end{array}$ & 3,93 & 4,00 & 5,00 & 1,71 \\
\hline & Padrões de desempenho ou metas a serem cumpridos. & 4,20 & 5,00 & 5,00 & 1,42 \\
\hline & $\begin{array}{l}\text { Processo de feedback que permite a comparação do } \\
\text { resultado das atividades com o padrão. }\end{array}$ & 4,33 & 5,00 & 6,00 & 1,95 \\
\hline & $\begin{array}{l}\text { Realimentação do sistema a partir de informações de } \\
\text { feedback quantitativas e qualitativas. }\end{array}$ & 3,93 & 4,00 & 5,00 & 1,71 \\
\hline & $\begin{array}{l}\text { Capacidade de modificar o comportamento do siste- } \\
\text { ma ou de atividades subjacentes. }\end{array}$ & 4,20 & 5,00 & 6,00 & 1,93 \\
\hline \multirow{4}{*}{ Administrativo } & $\begin{array}{c}\text { Direção para o comportamento da força de trabalho } \\
\text { por meio da organização dos indivíduos (desenho } \\
\text { organizacional e estrutura). }\end{array}$ & 4,40 & 5,00 & 6,00 & 1,92 \\
\hline & $\begin{array}{l}\text { Monitoramento do comportamento dos empregados e } \\
\text { dos responsáveis pelo seu monitoramento (governança). }\end{array}$ & 4,40 & 5,00 & 5,00 & 1,88 \\
\hline & $\begin{array}{c}\text { Especificação de como as tarefas ou comportamentos } \\
\text { devem ser realizados ou não realizados (políticas e } \\
\text { procedimentos). }\end{array}$ & 4,27 & 5,00 & 5,00 & 1,62 \\
\hline & $\begin{array}{c}\text { Agenda de reuniões executivas que estabelecem } \\
\text { prazos e direcionam o comportamento dos membros } \\
\text { da organização. }\end{array}$ & 4,93 & 5,00 & 6,00 & 1,62 \\
\hline \multirow{4}{*}{ Cultural } & $\begin{array}{l}\text { Valores, crenças e normas sociais que são estabelecidos } \\
\text { e influenciam o comportamento da força de trabalho. }\end{array}$ & 5,20 & 6,00 & 7,00 & 2,01 \\
\hline & $\begin{array}{l}\text { Procedimentos para recrutar e selecionar pessoas } \\
\text { seguem os valores da organização. }\end{array}$ & 4,67 & 4,00 & 4,00 & 1,40 \\
\hline & $\begin{array}{l}\text { Explicação do comportamento e dos valores organi- } \\
\text { zacionais desejados se refletem na força de trabalho. }\end{array}$ & 4,33 & 4,00 & 4,00 & 1,63 \\
\hline & $\begin{array}{l}\text { Hábitos de comunicação e de colaboração são meios } \\
\text { de controlar o comportamento da força de trabalho. }\end{array}$ & 4,13 & 4,00 & 4,00 & 1,68 \\
\hline
\end{tabular}

Fonte: Dados da pesquisa.

Observa-se, na Tabela 3, que, dentre as 16 formas de controle pesquisadas (assertivas), as que apresentaram maior formalidade e aderência nas empresas pesquisadas e de modo homogêneo foram: (i) definição das metas das áreas funcionais da organização para orientar os esforços e comportamentos; (ii) agenda de reuniões executivas que estabelecem prazos e direcionam o comportamento dos membros da organização; (iii) alinhamento dos objetivos, por meio das áreas funcionais da organização, com vistas a controlar as atividades de grupos e indivíduos; (iv) procedimentos para recrutar e selecionar pessoas que seguem os valores da organização; e (v) valores, crenças e normas sociais que são estabelecidos e influenciam o comportamento da força de trabalho.

Observa-se que o controle de planejamento e o controle cultural se sobressaem ao controle administrativo e o controle cibernético. Malmi e Brown (2008) mencionam que o planejamento é uma forma ex ante de controle, que define os objetivos das áreas funcionais da organização, direcionando o esforço e o comportamento. O controle cibernético apresenta menor grau de formalidade e encontra-se em intensidades distintas nas organizações, dada sua variabilidade nas respostas (desvio padrão). Nesse sentido, há indícios de que as empresas utilizam o planejamento (controle ex ante) e priorizam os controles mais informais, como, por exemplo, recrutar indivíduos que têm tipos particulares de valores que combinam com os da organização (MALMI; BROWN, 2008), em detrimento de controles mais formalizados, como o administrativo e o cibernético. 
Talvez a principal explicação para a maior formalização do controle de planejamento seja que estas empresas tiveram que apresentar um plano de negócios para o fundo de investimento e a incubadora. Raupp e Beuren (2011) averiguaram que os critérios mais utilizados pelas incubadoras brasileiras no recrutamento e seleção de empresas incubadas são viabilidade do negócio, característica inovadora do produto, tecnologia do produto, perfil empreendedor, setor de atuação do empreendimento, experiência do empreendedor no setor em que pretende atuar e processo de produção não poluente. Destaca-se, ainda, a importância do planejamento para as empresas incubadas. Machado et al. (2016) observaram que as empresas de insucesso comparativamente às incubadas que obtiveram êxito foram as que apresentaram menores índices em planejamento e execução do modelo de negócio.

No controle de planejamento, nota-se que as empresas possuem maior grau de formalização nas definições das metas das áreas funcionais, bem como o alinhamento dos objetivos dessas áreas. Contudo, apresentam menor formalidade no que concerne ao fornecimento dos padrões a serem alcançados em relação às metas, em que deixam evidente o nível de esforço e comportamento esperado. Tal fato pode ser um sinalizador de que as empresas pesquisadas estabelecem metas para áreas organizacionais, especificamente, de curto prazo e a nível operacional e, ao mesmo tempo, incentivam a experimentação, inovação, já que padrões de esforços, comportamentos e cumprimentos de metas ainda não são tão formalizados.

De Paula et al. (2015) ressaltam que os indicadores para o planejamento dos empreendimentos de incubadas devem se adequar aos problemas vivenciados pela empresa, e não o contrário. Asseveram que há um rol de indicadores e controles difundidos na literatura, para que cada empresa possa escolher aqueles que sejam mais adequados às suas necessidades e realidades, evitando, assim, um engessamento do processo inovativo e um desalinhamento entre os objetivos da empresa e os controles utilizados. De Paula et al. (2015, p. 250) mencionam ainda que "essa ampla gama de sugestões se justifica pela diferença existente entre as empresas, tanto no sentido de dificuldades enfrentadas e setor de atuação, quanto no nível de desenvolvimento em que elas se encontram”. Isso pode justificar a heterogeneidade de formalização dos controles evidenciados neste estudo.

Malmi e Brown (2008) explicam que existem duas abordagens amplas para o planejamento. A primeira é o planejamento de ações, no qual são estabelecidos os objetivos e ações para o futuro imediato, normalmente, um período de 12 meses ou menos. Isso tem um foco tático. A segunda abordagem ampla é o planejamento de longo prazo, no qual são estabelecidas as metas e ações para o médio e longo prazos. Isso tem um foco mais estratégico. Dos resultados apresentados, no que concerne ao controle de planejamento, há indícios de que as empresas focalizam o nível tático, pois a formalização maior ocorre no estabelecimento de metas e objetivos para áreas funcionais. Nesse sentido, denota-se que as empresas incubadas apresentam necessidades específicas, uma vez que possuem diferentes perfis de negócio, seja pela formação de sua equipe de gestão ou pelo tempo de funcionamento. Assim, cada caso deve ser tratado como único e deve ter soluções específicas para o apoio à gestão (COSTA; FRANÇA; TEIXEIRA, 2010).

Denota-se, também, que o controle cibernético apresenta intensidades de formalização distintas entre as empresas e inferiores em relação aos demais tipos de controle. Isso significa que as empresas incubadas ainda não estão tão preocupadas em estabelecer padrões de desempenho para medição, comparação e realimentação de informações. E, também, ainda não possuem institucionalizada a remuneração variável atrelada ao cumprimento de metas, especificamente, as financeiras. Conte, Beuren e Santos (2016) constataram, em sua pesquisa, que os instrumentos mais utilizados pelas empresas incubadas dizem respeito a questões pontuais, voltadas mais para a operacionalização da ideia proposta, em detrimento do uso de instrumentos para fins de controle. Esses achados podem explicar a baixa formalização do controle cibernético e do controle administrativo.

$\mathrm{Na}$ estatística descritiva do controle cibernético, nota-se que a capacidade de modificar o comportamento do sistema ou de atividades subjacentes e o processo de feedback que permite a comparação do resultado das atividades com o padrão apresentam elevada heterogeneidade nas respostas, como pode ser observado no desvio padrão. Já os padrões de desempenho ou metas a serem cumpridos apresentaram menor variabilidade nas respostas, mas seu grau de formalização é de nível intermediário. Tal fato pode estar relacionado com o resultado encontrado no controle de planejamento, no que concerne ao aspecto de formalização de fornecimento de padrões, metas, comportamentos esperados.

Evidências teórico-empíricas, como de Davila, Foster e Oyon (2009) e Amorim et al. (2016), apontam que essas organizações tendem a utilizar, em sua gestão, controle interativo em detrimento do controle diagnóstico, como é o caso do controle cibernético, com o intuito de estimular a troca de conhecimento, a criação de ideias e a inovação. Cassol et al. (2016) identificaram, em sua pesquisa, que a capacidade de usar o nível de conhecimento, experiência e competências na interpretação e assimilação de novos conhecimentos dos funcionários constitui-se em uma das práticas comuns de empresas incubadas, com o intuito de promover a inovação organizacional, de produtos e de processos.

No controle cultural, observa-se que se sobressaem os valores, crenças e normas sociais estabelecidos e que esses influenciam o comportamento da força de trabalho. De acordo com Lemon e Sahota (2004), uma forte cultura organizacional é importante, pois serve como repositório de conhecimento e, por sua vez, melhora a capacidade inovadora. Malmi e Brown (2008) consideraram três aspectos do controle cultural: controles baseados em valores, controles baseados em símbolos e controles de clãs. Neste estudo, observa-se uma ênfase maior nos controles baseados em valores. Os controles baseados em valores foram fundamentados no sistema de crenças de Simons (1995). Os sistemas de crenças comunicam os valores fundamentais da empresa, referem-se a um conjunto de definições organizacionais que os gestores seniores comunicam formalmente e reforçam sistematicamente para fornecer valores básicos, propósito e direção para a organização (SIMONS, 1995).

Malmi e Brown (2008) explicam que o impacto dos valores sobre o comportamento, institucionalizado por meio dos sistemas de crenças, funciona em três níveis. O primeiro é quando as organizações deliberadamente recrutam indivíduos que têm tipos particulares de valores que combinam com os da organização. O segundo é quando os indivíduos são 
socializados e têm seus valores alterados para se ajustar aos valores organizacionais. O terceiro é quando os valores são explicados e os funcionários se comportam de acordo com eles, mesmo que não tenham aderido a eles pessoalmente. As empresas incubadas apresentaram uma formalização semelhante e maior quanto aos procedimentos usados para recrutar e selecionar pessoas que seguem os valores da organização, o que pode sinalizar uma preocupação dos gestores com o capital intelectual dessas organizações. Cassol, Zalapai e Cintra (2017) observaram que o capital intelectual possui influência positiva sobre a inovação nas empresas incubadas. Comentam, ainda, que o capital intelectual da organização pode se tornar um diferencial competitivo e um potencializador da inovação.

No controle administrativo, observa-se maior aderência no estabelecimento de agenda de reuniões executivas que estabelecem prazos e direcionam o comportamento dos membros da organização. Contudo, o desenho da estrutura organizacional, o estabelecimento de políticas e procedimentos, assim como o de mecanismos de governança, apresentam-se de maneira heterogênea nas organizações pesquisadas. Tal fato pode estar relacionado com a fase e o tempo de incubação dessas empresas, fase de implementação e desenvolvimento do projeto, além dos recursos obtidos. Theiss e Beuren (2017) mencionam que, em empresas startups, assim como em incubadas, geralmente, não há códigos de conduta sofisticados, mas há comunicação com a força de trabalho para evitar o vazamento de informações confidenciais e a internalização de conhecimento do capital intelectual. Na fase inicial de uma empresa, os procedimentos e as rotinas não são formalmente estabelecidos (HORMIGA; BATISTA-CANINO; SÁCHEZ-MEDINA, 2011), nem mesmo o uso de indicadores e controles gerenciais é intensificado. À medida que as empresas se tornam mais maduras, graduadas, a complexidade da tomada de decisões e o processamento de informações aumentam, o que exige novas práticas de controle gerencial (MOORES; YUEN, 2001).

\section{CONCLUSÕES}

Este estudo fundamenta-se na proposição de Malmi e Brown (2008) de SCG como um pacote, que compreende controles de planejamento, cibernético, recompensa e compensação, administrativo e cultural. No entanto, o controle de recompensa e compensação não foi considerado, em função da premissa de os respondentes serem os proprietários das empresas incubadas, o que foi confirmado no perfil dos respondentes. Assim, este estudo objetivou analisar a formalidade dos Sistemas de Controle Gerencial em empresas incubadas.

De modo geral, observa-se maior formalização no controle de planejamento e controle cultural em detrimento do controle administrativo e controle cibernético. Esses resultados coadunam com o entendimento de Haustein, Luther e Schuster (2014) de que as empresas altamente inovadoras experimentam dificuldades para equilibrar a necessidade de controle de seus negócios com a exigência de flexibilidade para poder gerar inovações. As evidências apontam que as empresas pesquisadas priorizam o planejamento de metas e ações de curto prazo, com foco mais tático (MALMI; BROWN, 2008), e os controles informais, enraizados em crenças organizacionais e valores (RICCABONI; LEONE, 2010), em detrimento dos controles mais formais, que são exercidos a partir do estabelecimento de medidas explícitas e verificáveis (NORRIS; O'DWYER, 2004). Contudo, a adoção de controles gerenciais formais na fase inicial é importante para o crescimento dessas empresas (DAVILA; FOSTER, 2005).

A ênfase na inovação de produtos ou na satisfação do cliente, por exemplo, pode ser apoiada pelo uso de medidas de desempenho não financeiras, conforme apontado por Baines e Langfield-Smith (2003). No entanto, parcimônia é necessária pelo fato de a pesquisa ter-se concentrado em quatro dos cinco tipos do pacote de controles de Malmi e Brown (2008). Logo, não é possível extrapolar as evidências deste estudo aos demais mecanismos de controle. A preocupação foi com o grau de formalidade dos controles dos SCG nas empresas incubadas, e não com o pacote. Desse modo, pesquisas futuras podem abranger todos os elementos do pacote, verificando o impacto nos resultados do grau de formalização com a inclusão do controle de recompensa e compensação.

Este estudo contribui com a literatura ao abordar o grau de formalidade dos SCG em empresas incubadas, em sua essência, empresas startups, particularmente, dos controles de planejamento, cibernético, administrativo e cultural. Contribui, também, ao mostrar a formalidade dos SCG em ambientes inovadores, de jovens empresas e geralmente de pequeno porte, o que amplia as discussões sobre os efeitos dos SCG na inovação de empresas com esse perfil. O estudo também apresenta contribuições práticas para as empresas incubadas, especialmente sobre os aspectos que caracterizam o grau de formalidade de cada controle.

Ressalta-se, como principal limitação do estudo, a possivel associação do grau de formalidade com a estratégia de cada empresa incubada e com o seu estágio de incubação. Outro aspecto limitador da pesquisa é a pequena amostra de gestores respondentes, o que impediu a aplicação de testes estatísticos mais robustos, de modo a capturar possíveis efeitos entre o perfil dos respondentes, características das empresas e as variáveis relativas ao grau de formalidade dos controles do pacote de SCG.

\section{REFERÊNCIAS}

ALVES, A. B. Desenho e uso dos sistemas de controle gerencial e sua contribuição para a formação e implementação da estratégia organizacional. 2010. 112f. Dissertação (Mestrado em Controladoria e Contabilidade) - Universidade de São Paulo, São Paulo, 2010.

AMORIM, B. C. et al. Sistema de controle orçamentário e inovação: Um estudo em empresas de base tecnológica incubadas. Espacios, v. 37, n. 15, p. 6-13, 2016. 
ANTHONY, R. Planning and control Systems: A framework for analysis. Boston: Division of Research, Harvard University Graduate Business School of Business Administration, 1965.

BAINES, A.; LANGFIELD-SMITH, K. Antecedents to management accounting change: a structural equation approach. Accounting, Organizations and Society, v. 28, n. 7, p. 675-698, 2003.

BEDFORD, D. S.; MALMI, T.; SANDELIN, M. Management control effectiveness and strategy: An empirical analysis of packages and systems. Accounting, Organizations and Society, v. 51, p. 12-28, 2016.

BERGEK, A.; NORRMAN, C. Incubator best practice: A framework. Technovation, v. 28, n. 1, p. 20-28, 2008.

BEUREN, I. M.; VAZ, P. V. C. Papel mediador do pacote do sistema de controle gerencial na relação entre estratégia ambiental e performance gerencial. In: Congresso USP de Controladoria e Contabilidade, 16., 2016, São Paulo. Anais eletrônicos... São Paulo, FEA/ USP, 2016.

CASSOL, A. et al. Desenvolvimento da capacidade absortiva em empresas incubadas e graduadas de Santa Catarina, Brasil. Desenvolvimento em Questão, v. 14, n. 37, p. 168-201, 2016.

CASSOL, A.; ZAPALAI, J.; CINTRA, R. F. Capacidade absortiva como propulsora da inovação em empresas incubadas de Santa Catarina. Revista Ciências Administrativas, v. 23, n. 1, p. 9-41, 2017.

CHENHALL, R. H. Management control systems design within its organizational context: findings from contingency-based research and directions for the future. Accounting, Organizations and Society, v. 28, n. 127-168, 2003.

CONTE, A.; BEUREN, I. M.; SANTOS, V. Uso de instrumentos do sistema de controle gerencial em empresas incubadas. In: Congresso de Contabilidade da UFRGS, 1., Porto Alegre, 2016. Anais eletrônicos... Porto Alegre: UFRGS, 2016.

COSTA, L. F. S.; FRANÇA, M. C. L.; TEIXEIRA, R. M. Apoio gerencial na incubação de empresas de base tecnológica: O caso da Incubadora Cise. Revista Pensamento Contemporâneo em Administração, v. 4, n. 1, p. 1-15, 2010.

DAVILA, A.; FOSTER, G.; JIA, N. The valuation of management control systems in start-up companies: International Field-Based Evidence. European Accounting Review, v. 24, n. 2, p. 207-239, 2015.

DAVILA, T.; FOSTER, G. Startup firms' growth, management control systems adoption, and performance. IESE Business School: University of Navarra, 2005

DAVILA, A.; FOSTER, G.; OYON, D. Accounting and control, entrepreneurship and innovation: Venturing into new research opportunities. European Accounting Review, v. 18, n. 2, p. 281-311, 2009.

DE PAULA, H. C. et al. Mensuração da inovação em empresas de base tecnológica. RAI. Revista de Administração e Inovação, v. 12 , n. 4 , p. 232-253, 2015

FERREIRA, A.; OTLEY, D. T. The design and use of performance management systems: An extended framework for analysis. Management Accounting Research, v. 20, n. 4, p. 263-282, 2009.

GRABNER, I.; MOERS, F. Management control as a system or a package? Conceptual and empirical issues. Accounting, Organizations and Society, v. 38, n. 6, p. 407-419, 2013.

HAUSTEIN, E.; LUTHER, R.; SCHUSTER, P. Management control systems in innovation companies: A literature based framework. Journal of Management Control, v. 24, n. 4, p. 343-382, 2014.

HENRI, J. F. Management control systems and strategy: A resource-based perspective. Accounting, Organizations and Society, v. 31 , n. 6, p. 529-558, 2006 .

HORMIGA, E.; BATISTA-CANINO, R. M.; SÁNCHEZ-MEDINA, A. The impact of relational capital on the success of new business start-ups. Journal of Small Business Management, v. 49, n. 4, p. 617-638, 2011.

IACONO, A.; ALMEIDA, C. A. S.; NAGANO, M. S. Interação e cooperação de empresas incubadas de base tecnológica: uma análise diante do novo paradigma de inovação. RAP. Revista de Administração Pública, v. 45, n. 5, p. 1485-1516, 2011.

LEMON, M.; SAHOTA, P. S. Organizational culture as a knowledge repository for increased innovative capacity. Technovation, v. 24, n. 6, p. 483-498, 2004.

LOPES, I. F.; BEUREN, I. M.; MARTINS, G. D. Alinhamento entre uso de instrumentos do sistema de controle gerencial e inovação de produtos e processos. Revista Organizações em Contexto, v. 14, n. 27, p. 1-27, 2018.

MACHADO, E. et al. Análise da influência do capital estrutural no sucesso de startups incubadas: Uma pesquisa com 21 empreendedores. International Journal of Innovation, v. 4, n. 1, p. 46-57, 2016.

MALMI, T.; BROWN, D. Management control systems as a package - Opportunities, challenges and research directions. Management Accounting Research, v. 19, p. 287-300, 2008.

MOORES, K.; YUEN, S. Management accounting systems and organizational configuration: a life-cycle perspective. Accounting, Organizations and Society, v. 26, n. 4, p. 351-389, 2001. 
NORRIS, G.; O’DWYER, B. Motivating socially responsive decision making: the operation of management controls in a socially responsive organisation. The British Accounting Review, v. 36, n. 2, p. 173-196, 2004.

OTLEY, D. T. The contingency theory of management accounting: achievements and prognosis. Accounting, Organizations and Society, v. 5, n. 4, p. 413-428, 1980.

OUCHI, W. A conceptual framework for the design of organizational control mechanisms. Management Science, v. 25, n. 9, p. 833848,1979

OYADOMARI, J. C. T. Uso do sistema de controle gerencial e desempenho: Um estudo em empresas brasileiras sob a ótica da VBR (Visão Baseada em Recursos). 2008. 130f. Tese (Doutorado em Controladoria e Contabilidade) - Universidade de São Paulo, São Paulo, 2008.

RAUPP, F. M.; BEUREN, I. M. Perfil do suporte oferecido pelas incubadoras brasileiras às empresas incubadas. REAd. Revista Eletrônica de Administração, v. 17, n. 2, p. 330-359, 2011.

RICCABONI, A.; LUISA LEONE, E. Implementing strategies through management control systems: the case of sustainability. International Journal of Productivity and Performance Management, v. 59, n. 2, p. 130-144, 2010.

ROETZEL, P. G.; STEHLE, A.; PEDELL, B. Using an environmental management control system to translate environmental strategy into managerial performance. In: American Accounting Association Annual Meeting and Conference on Teaching and Learning in Accounting, 2014, Atlanta, Georgia. Annals... Atlanta, Georgia: American Accounting Association, 2014.

SCHEIN, E. H. Organizational culture and leadership. 2 ed. San Francisco: Jossey-Bass, 1997.

SIMONS, R. Control in an age of empowerment. Harvard Business Review, v. 73, n. 2, p. 8-88, 1995.

THEISS, V.; BEUREN, I. M. Reflexos da aplicação de recursos por provedores de funding no uso do sistema de controle gerencial mediado pelo seu desenho em empresas startups. In: USP International Conference in Accounting, 17., 2017, São Paulo. Anais eletrônicos... São Paulo: FEAUSP, 2017.

WIDENER, S. K. An empirical analysis of the levels of control framework. Accounting, Organizations and Society, v. 32, n. 7-8, p. 757-788, 2007. 